
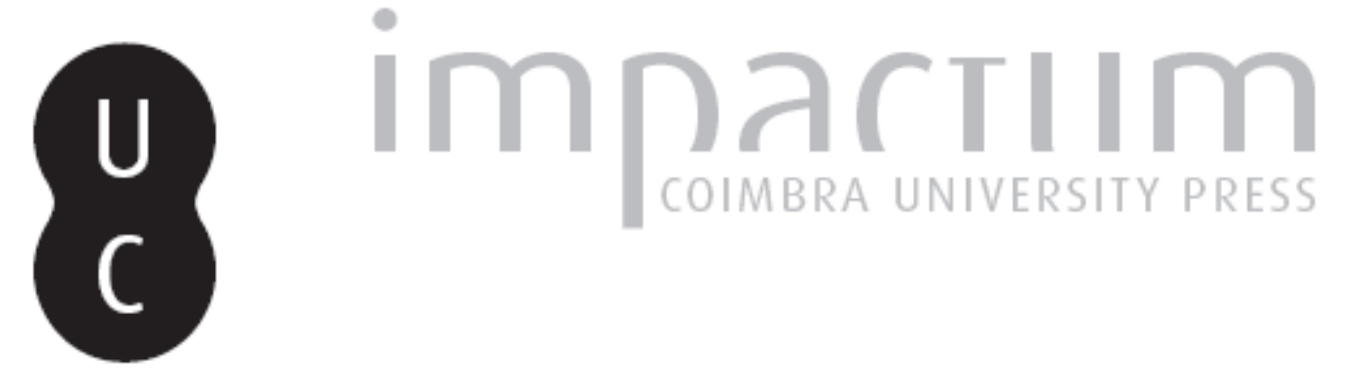

\title{
[Recensão a] Juan Manuel ABASCAL PALAZÓN, Los Nombres Personales en las Inscripciones Latinas de Hispania
}
Autor(es):
D’Encarnação, José

Publicado por: Imprensa da Universidade de Coimbra

URL persistente:

URI:http://hdl.handle.net/10316.2/45414

DOI:

DOI:https://dx.doi.org/10.14195/1647-8657_37_12

Accessed : $\quad$ 26-Apr-2023 13:25:28

A navegação consulta e descarregamento dos títulos inseridos nas Bibliotecas Digitais UC Digitalis, UC Pombalina e UC Impactum, pressupõem a aceitação plena e sem reservas dos Termos e Condições de Uso destas Bibliotecas Digitais, disponíveis em https://digitalis.uc.pt/pt-pt/termos.

Conforme exposto nos referidos Termos e Condições de Uso, o descarregamento de títulos de acesso restrito requer uma licença válida de autorização devendo o utilizador aceder ao(s) documento(s) a partir de um endereço de IP da instituição detentora da supramencionada licença.

Ao utilizador é apenas permitido o descarregamento para uso pessoal, pelo que o emprego do(s) título(s) descarregado(s) para outro fim, designadamente comercial, carece de autorização do respetivo autor ou editor da obra.

Na medida em que todas as obras da UC Digitalis se encontram protegidas pelo Código do Direito de Autor e Direitos Conexos e demais legislação aplicável, toda a cópia, parcial ou total, deste documento, nos casos em que é legalmente admitida, deverá conter ou fazer-se acompanhar por este aviso.

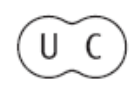


UNIVERSIDADE DE COIMBRA

FACULDADE DE LETRAS

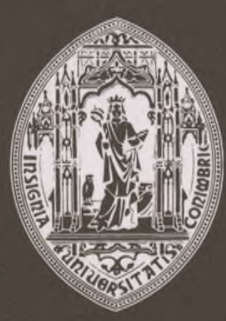

\section{CONIMBRIGA}

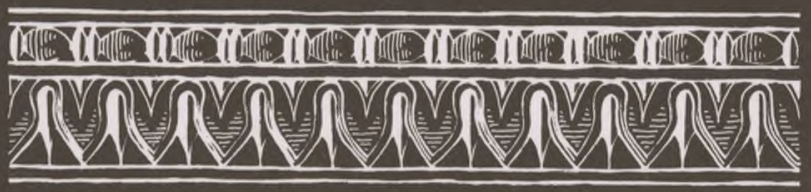

VOLUME XXXVII - 1998 
manancial histórico-epigráfico aqui reunido, tarefa que terá reservado para uma outra oportunidade. Alguns dos aspectos que foquei, e outros, contribuirão para o esclarecimento da história romana de Palência.

Nesse aspecto cumpre saudar a obra como livro de consulta fundamental. Dispondo de índices pormenorizados e bem organizados (a que apenas faltará um índice geográfico) vem facilitar o trabalho a epigrafistas e historiadores.

FERNANDA REPAS

Juan Manuel ABASCAL PALAZÓN, Los Nombres Personales en las Inscripciones Latinas de Hispania. (Antigüedad y Cristianismo, II), Murcia, 1994, 554 pp., ISBN 84-7684-517-0.

Os estudos onomásticos estão a assumir um papel cada vez mais relevante no ámbito da pesquisa em Historia Antiga.

$\mathrm{Na}$ verdade, gravado habitualmente na perenidade do mármore, o nome revela a imagem que se pretendeu transmitir e denuncia estatuto social, origem étnica ou, simplesmente, a moda.

Por isso, desde que, em meados do século passado, a Epigrafia ganhou foros de ciência imprescindível para melhor se conhecer a Antiguidade Clássica, o rol dos antropónimos atestados nas epígrafes, quer numa região determinada do mundo romano quer em todo o Império, passou a ser instrumento de trabalho indispensável. E, por isso, os corpora de inscrições nunca estariam completos se não tivessem índices onomásticos cuidadosamente elaborados.

Iiro Kajanto analisou os cognomes latinos, numa obra (The Latin Cognomina, Helsínquia, 1965, Roma, 1982) que, ainda hoje, é de referência obrigatória. Heikki Solin proporcionou-nos, após longo trabalho de pesquisa, um elenco exaustivo dos nomes gregos registados na epigrafia de Roma (Die Griechischen Personennamen In Rom - Ein Namenbuch, Walter de Gruyter, Berlim, 1982), que constitui necessário elemento de comparação nesse domínio. Antes dele, procurara Wilhelm Schulze (Zur Geschichte Lateinischer Eigennamen, Berlim, 1966) traçar uma panorâmica da onomástica latina, baseada, porém, em pressupostos da época que se inclinavam para ver em todos os radicais 'ressonâncias' etruscas. Para actualizar esses trabalhos (e já com o recurso, que vai ser cada vez mais oportuno, da informática), Solin e Salomies deram a lume o Repertorium Nominum Gentilium et Cognominum Latinorum (Nova Iorque, 1988) - vide Conimbriga 301991 172-174. Por outro lado, o fecundo manancial 
de L'Année Épigraphique ficaria também facilmente ao dispor dos investigadores através do labor paciente de Jean-Marie Lassère: Tables Générales de L'Année Epigraphique 1961-1980 (Presses Universitaires de France, Paris, 1992).

Para a Península Ibérica - porquanto a acessibilidade aos índices de CIL II nunca foi grande, dada a raridade de exemplares existentes dispúnhamos, fundamentalmente, dos índices das Inscripciones Latinas de la España Romana, de José Vives (Barcelona, 1972). Apesar das inúmeras correcções por fazer (vide Conimbriga 151976 179-182), funcionou como útil termo de comparação, porque, recorde-se, reuniu, por categorias, perto de 7000 textos peninsulares. No entanto, interessava, de modo particular, a onomástica latina de raiz pré-romana, um campo de investigação a que se dedicaram Palomar Lapesa, estudando os antropónimos da Lusitânia (La Onomástica Personal Pré-Latina de La Antigua Lusitania, Salamanca, 1957), e María Lourdes Albertos, cuja obra La Onomástica Personal Primitiva de Hispania Tarraconense y Betica tardou, porém, a sair (Salamanca, 1966). Entretanto, Jürgen Untermann deu corpo a uma ideia que já pairava no ar: a elaboração de mapas que mostrassem a distribuição geográfica dos vários antropónimos típicos ou mais frequentes no território peninsular, a fim de se detectarem pontos de contacto, que, eventualmente, trouxessem luz sobre etimologias diferenciadas, passíveis de virem a ser postas em paralelo com os vestígios arqueológicos: os seus Elementos de un Atlas Antroponimico de la Hispania Antigua Madrid, 1965) traçaram, desde logo, hipóteses de trabalho que o aumento considerável de testemunhos tem vindo a confirmar.

E se o aparecimento de Hispania Epigraphica (vide Conimbriga 301991 178-181) veio colmatar a lacuna deixada em aberto pelo desaparecimento precoce da Hispania Antiqua Epigraphica, o certo é que se fazia sentir, apesar de tudo, a falta de um livro onde, rapidamente, o investigador pudesse verificar a ocorrência, na Península Ibérica, do antropònimo que acabara de 1er - ou que tinha dificuldade em decifrar - na inscrição nova que se lhe apresentara.

Bem andou, pois, Juan Manuel Abascal em meter ombros à tarefa, que solidamente alicerçou numa exaustiva pesquisa bibliográfica, onde rara será a publicação que falte. Afirma o autor, no prólogo, que a obra começou por ser mero "ficheiro pessoal" que, pouco a pouco, foi crescendo, até se converter num "repertório de antroponimia hispana em língua latina". E, não obstante afirmar que mais não é que "ferramenta de transição" - pois estão em curso, por exemplo, a publicação da segunda edição do Corpus Inscriptionum Latinarum peninsular e a elaboração de um atlas antroponimico da Lusitânia - o certo é que não deixa de referir que, desta sorte, já é possível analisar mais detidamente "a concentração de determinados gentilicios em espaços geográficos muito reduzidos, a distribuição de um escol por um território específico ou os múltiplos aspectos derivados do desconhecimento da língua escrita por amplos sectores da população".

Conimbriga, 37 (1998) 267-310 
Merece leitura atenta a Introdução.

Primeiro, judiciosas considerações metodológicas: incluem-se as "inscrições latinas achadas na Hispânia, independentemente da origem dos personagens" nelas mencionados; só se excluem os textos reproduzidos mecanicamente (v. g., marcas de oleiro), mas consideram-se "os magistrados monetários das séries latinas de Hispânia"; a base da pesquisa foi predominantemente bibliográfica; simplificaram-se ao máximo as referências bibliográficas.

Depois, Juan Manuel Abascal não resistiu a gizar, desde já, a panorâmica que o material acumulado (“informação onomástica acerca de 19593 indivíduos”!) lhe possibilitava, tanto do ponto de vista estatístico como qualitativo, não obstante se ter em conta que se trata de uma amostra que se estende por um período de duzentos e cinquenta anos, o que faz com que "cada momento, cada região, cada âmbito urbano se caracterize por um hábito epigráfico específico em que entram em jogo a vitalidade dos meios indígenas, o progresso da latinidade, a mobilidade geográfica, etc.” (p. 26). Assim, e a título de exemplo, verifica-se que a identificação mediante os tria nomina apresenta, no conjunto, uma percentagem relativamente elevada $(24,74 \%)$, atendendo "ao forte volume de textos pertencentes à costa da Tarraconense e Bética e ao considerável volume de inscrições hispanas datáveis de entre fins do século I d. C. e o final dos Antoninos" (pp. 27-28), o que deixa na sombra a notável "escassez de tria nomina no Noroeste, a sua absoluta ausência no mundo dos Vadinienses ou o elevado número de escravos dos grandes centros urbanos" (p. 28).

Analisa o autor o que se passa com os praenomina (Lucius é o mais popular); com os gentilicios (apenas 10 ultrapassam os 200 testemunhos, e os Iulii mantêm a sua natural posição de supremacia, sendo significativo o que ocorreu no territorio olisiponense); com os nomes únicos e os cognomina: Ambatus, Tanginus e Boutius ocupam o lugar cimeiro entre os nomes de cariz indígena, Severus possui "claro protagonismo" entre os cognomes de etimologia latina documentados (258 casos em 2962).

As considerações feitas a propósito da onomástica indígena (pp. 31-35), da onomástica de origem grega (pp. 35-36) e da onomástica latina constituem, igualmente, motivo do maior interesse, pelas actualizações - inclusive metodológicas - que aponta. Recordaria, a propósito, duas passagens, em meu entender, deveras significativas, que vêm ao encontro do que já temos referido: o Latim pode ser a língua universal da Hispânia do Alto Império, "mas não é uma escrita universal", "pois a compreensão escrita nunca chegou a ser absoluta" (p. 35) e "as formas orais impuseram-se ante o desconhecimento das grafias" (p. 36). Daí, o aparecimento de tantas variantes do mesmo antroponimo. Por outro lado, Abascal Palazón acentua um dado a que, porventura, nem sempre se terá atribuído o grande valor que detém: a moda. "A moda parece estar por cima de tudo" (p. 37) - em cada período, em cada região... E no que concerne,

Conimbriga, 37 (1998) 267-310 
norneadamente, à adopção da onomástica de raiz grega sabemo-lo perfeitamente, mas nunca é de mais repetir.

Antes de entrar no "dicionário" (digamos assim) que constitui o cerne da obra, Juan Manuel Abascal demora-se a dar o rol dos gentilicios que devem ser banidos, como tais, da obra, já referida, de Solin e Salomies; dos nomes a excluir das listas de Palomar e de Lourdes Albertos; enumerando, ainda (p. 59), os gentilicios que aparecem na posição de cognomen.

O que fica dito é bastante para dar conta da extrema oportunidade deste volume, resultado do esforço editorial conjunto das universidades de Múrcia e Complutense de Madrid, mormente pelo acervo documental nele criticamente apresentado. Obra doravante de consulta fundamental, vade-mecum permanente de quantos têm nas fontes epigráficas um elemento de referência indispensável.

Ponto de chegada, é (passe o obrigatório lugar-comum) desde logo um ponto de partida, sujeito a correcções, acrescentos, ajustamentos pontuais... Creio, até, que o Autor deveria ter indicado, no final do prólogo, para onde deveria ser remetida a correspondência: qual o seu endereço electrónico ou outro, a fim de que, à medida que a consulta ou a investigação nos trouxerem novos elementos, de pronto os possamos fazer chegar ao seu conhecimento, numa acção conjunta que a todos interessa.

E é precisamente com esse espírito que adiantaria algumas observações:

$\mathrm{Na}$ pág. 55, s. v. "Tallici", Alvega é dada como pertencente ao distrito de Setúbal; trata-se duma freguesia do concelho de Abrantes, distrito de Santarém.

- Iallius (p. 151): pese, muito embora, a certeza em contrário do editor do $\mathrm{AE}$ (1992 951), uma observação mais atenta da fotografia do monumento comemorativo da oferta de um relógio à civitas Igaeditanorum (AE 1961149 = 1967 144) permite-nos concluir, como já ti ve ocasião de o afirmar (Conimbriga 301991 181), que estamos perante o gentilicio Tallius.

L. Manlius "Almus" (p. 180): trata-se do nome registado na célebre inscrição rupestre do Castro dos Três Rios. Temo-lo considerado um texto votivo, eventualmente dedicado a umas divindades indígenas, os Dii Perniici: cf. as minhas Divindades Indigenas sob o Domínio Romano em Portugal, Lisboa, 1975, 257-258, onde segui a interpretação proposta por Jürgen Untermann (AEA 381965 8-17). Aliás, é essa referência que vem na mesma página 180 , na $2^{\text {a }}$ coluna, não se tendo apercebido o Autor que se trata do mesmo testemunho (há também duplicação s. v. Tureius, p. 534). Já hoje não temos dúvidas acerca da tribo a que L. Manlius pertence: é mesmo a tribo Aemilia, não obstante se encontrar escassamente documentada na Península Ibérica (cf. Rainer Wiegels, Die Tribuschriften des Römischen Hispanien - Ein Katalog, Berlim, 1985, 87 e 84). Também parece legítimo considerar ALMVS a fórmula votiva. Lúcio Mânlio integrou, decerto, uma das primeiras levas de colonos itálicos na Lusitânia e que, por isso mesmo, se apressou a venerar as divindades locais para que lhe fossem

Conimbriga, 37 (1998) 267-310 
propícias. Tureius é, ao invés, confirmadamente, um antropònimo indígena, e não um nomen, como Abascal Palazón bem salienta (p. 534), equivalente a Tureus, não nos sendo possível optar por uma forma ou por outra, sempre que a palavra nos surge no genitivo Turei. No Castro dos Três Rios, a palavra pertence, porém, a uma segunda inscrição.

- Pontilius (p. 202): sabemos que os Romanos praticavam, em Epigrafia, o «culto da ambiguidade», sempre que duma ambiguidade de leitura ou de interpretação pudesse resultar benefício. Não vejo, porém - como quer Maria Adela Barreda Pascual («Algunos unica de la epigrafia republicana de Hispania: Pontilienus, Utius, Trinius y Labicius», XI Congresso Intemazionale di Epigrafia Greca e Latina - Preatti, Roma, 18-24/09/1997, p. 81-90) - que o genitivo Pontili (de CIL II 3433) se deva considerar pertencendo a Pontilienus, só porque este antropònimo se encontra documentado e Pontilius é um unicum na Península Ibérica.

- Apaño (p. 279: corrige-se bem a leitura do texto do Fundão (AE 1977 363), que eu já assinalara em IRCP, p. 495; deve, porém, integrar-se também o testemunho incluído s. V. “Apaionis” (AE 1971 167), que resulta, na verdade, de uma leitura deficiente, pois há um nexo NA.

- Clodamenis (p. 331): patronímico indígena dum eventual L. Sestius Corocaurus assim interpretado por Hübner (CIL II2462 e 5611), será melhor considerá-lo duvidoso, atendendo à revisão efectuada por Armando Coelho Ferreira da Silva (Cadernos de Arqueologia, Braga, 11984 40-43): o texto, gravado numa estátua de guerreiro, é mais longo e de interpretação (ainda) difícil na sua totalidade.

- Langonus (?) (p. 396): tem Juan Manuel Abascal inteira razão, ao duvidar desta proposta de leitura apresentada pelo editor do AE 1982, 478. Trata-se, de facto, do cognome grego Langon, como claramente se afirma em FE $41982 \mathrm{n}^{\circ}$ 15, onde esta epígrafe de Póvoa de Atalaia veio publicada.

- Sanecius (p. 495): leitura do cognome de Ti(berius) Claudius, dedicante, em Numão, duma ara Dis Deabusq(ue) Coniumbric(ensium) que se fundamenta na hipótese interpretativa dos autores de Fouilles de Conimbriga II (Paris, 1976, $\mathrm{n}^{\circ}$ 3), seguida por Patrick Le Roux (LArmée Romaine et T Organisation des Provinces Ibériques d Auguste à Tinvasion de 409, Paris 1982, 191, n 73). Já em Divindades Indígenas... (p. 176) defendi a leitura Sailcius. Baseei-me, é certo, na fotografia; mas já então não havia modo melhor de estudar o monumento, porquanto dispunha de uma excelente foto gentilmente cedida pelo Dr. J. A. Pinto Ferreira, tirada quando a superfície epigrafada ainda não sofrera a corrosão a que, ao longo dos anos, tem sido submetida, a ponto que, hoje, alguns caracteres não se distinguem já. Penso, pois, que, ao contrário do que se sugere na p. 54, não será de excluir-se Sailcius $=$ Sailgius, foneticamente equivalente às formas em -e- (Saelcius e Saelgius), mais documentadas.

JOSÉ D’ENCARNAÇÃO

Conimbriga, 37 (1998) 267-310 